\title{
Imagens da indústria automotiva para consumo: \\ o mundo do trabalho na ótica da comunicação publicitária ${ }^{1}$
}

\section{Vander Casaqui}

\section{Resumo}

Este artigo analisa as estratégias da comunicação publicitária da indústria de automóveis no início do século XXI, tendo como eixos principais as representações de seus processos produtivos e os significados do consumo. 0 quadro teórico discute as teorias de McLuhan sobre os aspectos culturais do automóvel, as tendências da produção e os novos papéis a serem assumidos pelo consumidor, nas transformações promovidas pelo marketing moderno. A abordagem teórico-metodológica da Análise do Discurso de linha francesa foi adotada na reflexão sobre o corpus.

\section{Palavras-chave}

Comunicação e consumo. Comunicação e trabalho. Publicidade. Marcas de automóveis. Marshall McLuhan.

\section{Vander Casaqui I vcasaqui@espm.br}

Doutor em Ciências da Comunicação pela Universidade de São Paulo (USP). Professor do Programa de Pós-Graduação em Comunicação e Práticas de Consumo (PPGCOM) da Escola Superior de Propaganda e Marketing (ESPM).

\section{Introdução}

Em suas reflexões sobre a publicidade no livro

Understanding Media, McLuhan alertava

que, algum dia, historiadores e arqueólogos

descobririam que os anúncios eram os mais ricos

e fiéis reflexos que uma sociedade pode conceber para retratar os seus setores de atividades.

Neste trabalho, investigamos como a linguagem publicitária permite que analisemos a atualização das mitologias em torno dos automóveis no século XXI, em que corporações multinacionais do setor automobilístico concebem sua comunicação na intersecção entre aspectos globais e locais. Por meio das campanhas de automóveis selecionadas para este estudo, destacamos as estratégias de representação do mundo do trabalho, como forma de constituir vínculos com o cotidiano dos consumidores, com a experiência vivida na prática laboral e sua superação através do universo onírico-lúdico sustentado pela 
publicidade. A inclusão da experiência do público é uma tendência já apontada por McLuhan no contexto em que analisou a produção midiática, e que tem se confirmado e aprofundado com o passar do tempo, ainda mais quando consideramos a internet como suporte para a inclusão dos consumidores em processos colaborativos relativos a produtos, serviços e ao próprio desenvolvimento da comunicação que vai constituir a estética midiática da mercadoria.

A publicidade, como óculos sociais que mediam nosso olhar para a vida, para as relações entre sujeitos, entre sujeitos e objetos, constantemente volta-se para o mundo do trabalho. Os sistemas produtivos, os trabalhadores, as origens das mercadorias, são campo fértil para a criatividade publicitária, que desenvolve versões lúdicas, oníricas, cômicas, poéticas dos processos de elaboração dos produtos, de acordo com 0 universo simbólico das suas marcas. Neste trabalho, voltamos nosso foco para a comunicação publicitária da indústria de automóveis, para analisar as significações dessa tradução da esfera produtiva e do trabalho a fim de servir às estratégias de persuasão e sedução de marcas globais. De acordo com John Berger (1974), a publicidade é "o processo de fabricar fascinação". Nosso interesse em relação a esse tema está baseado na questão: de que forma a publicidade recupera, traduz, envolve de magia e imaginação uma esfera tão complexa como é o mundo do trabalho, a ponto de ele se transformar em mote para o consumo das mercadorias?

Com a divisão do trabalho e a mercadorização do trabalhador no contexto do capitalismo moderno, essa esfera de atuação humana, de acordo com Marx, gerou o distanciamento entre produtor e produto. Dessa forma, o trabalho, que potencialmente é uma forma de realização das capacidades humanas mais profundas, de produção de subjetividade e identidade, em decorrência da aplicação dos métodos de administração do trabalho, como o taylorismo/fordismo, tornase "trabalho estranhado" (MARX, 2004), como bem demonstra Charles Chaplin, em seu filme Tempos Modernos (1936). Contemporaneamente, a intensificação do trabalho, a concorrência, as pressões e exigências em torno do desempenho do trabalhador, são causadores de uma série de males que atingem o homem de nossos dias. Por mais que o trabalho também possa exprimir as buscas e os sonhos de parcelas de sujeitos, há uma aura "pesada" em torno da atividade profissional humana. Levando em consideração esse contexto, a função de tradução, de releitura da linguagem publicitária ganha maior relevância para compreensão dos processos simbólicos que envolvem o consumo em nossa sociedade. É através da comunicação voltada à promoção do consumo, no caso da linguagem publicitária, que 0 ambiente 
fabril dos automóveis, lugar primeiro onde a linha de produção nos moldes concebidos por Henry Ford foi instalada, pode se transformar em lugar de despertar dos desejos e da sedução.

\section{$2 \mathrm{~A}$ aldeia global e a edição do mundo pela publicidade}

Os processos de midiatização das corporações têm na publicidade uma linguagem que organiza as coisas do mundo, editando-o em função da presença do anunciante e dos significados a ele associados. Dessa forma, constituem-se comunidades imaginadas (ANDERSON, 2005), que, distintas do sentimento de nação estudado por Anderson, são constituídas por identificações através de comunidades de gosto e práticas de consumo. Consumidores de bens produzidos por corporações multinacionais são alinhados, por meio da comunicação publicitária, a estilos de vida que têm conexão direta com 0 "espírito" da mercadoria anunciada.

Os automóveis estão entre os principais bens de consumo que tem essa característica de corresponder a estratégias globais de produção e comunicação. Podemos compreender 0 pensamento de McLuhan em torno do automóvel tanto em sua inserção na cultura, por meio de seu consumo que se traduz em uma extensão do homem com características próprias, quanto em relação com as transformações das cadeias produtivas que 0 autor identificava para um futuro próximo. Discutiremos a seguir esses dois aspectos que fazem do automóvel um dos bens de consumo mais recorrentes na obra do pensador.

Em sua obra Understanding Media, McLuhan (1995, p. 254) associa o automóvel a uma peça de roupa, uma extensão humana que representaria uma "carapaça, a concha protetora e agressiva do homem urbano e suburbano". Como organizadora do olhar do autor para 0 veículo e sua relação com os sujeitos, especialmente os que vivem nas cidades, há a concepção de que a tecnologia expande os sentidos e 0 alcance das ações humanas. Nesse sentido, o automóvel seria uma forma de mediação do homem com as coisas do mundo e com o outro, um mediador que promove uma interação outra com o espaço. Se a mídia, tal qual pensada por McLuhan, tem como característica a transformação da percepção do homem, o meio em si que massageia nossos sentidos e estimula um novo sensório, 0 automóvel também pode ser considerado uma mediação da experiência humana.

Além do sentido da proteção, há a remodelação dos espaços e da organização das cidades decorrentes do uso do carro; a projeção do homem no contexto urbano é, em última instância, o estabelecimento de novos parâmetros das relações entre sujeito, tempo e espaço. Fazemos aqui uma aproximação das reflexões de McLuhan com as questões que permeiam as teorias de Walter Benjamin (1991) em relação às Exposições Universais, às 
passagens e à reprodutibilidade técnica da arte (especificamente a cinematográfica), enfim, da cultura visual que se estabelece no século XIX e vai produzir novas sensibilidades humanas a partir das formas de olhar. McLuhan vai ampliar a dimensão das transformações dos seres humanos a partir do advento das tecnologias da informação; em sua leitura, a experiência humana, em ambientes de afetação contínua pelos usos das tecnologias, vai resultar em novas estruturas mentais. 0 ser imerso na aldeia global e estimulado pela mídia de McLuhan vai gerar outras características para o novo sensório discutido por Benjamin.

0 segundo aspecto se refere à instância da produção que, para McLuhan (1995, p. 251), estaria prestes a viver uma grande revolução, que é marcada pela produção de objetos "únicos, sob medida, ao mesmo preço e velocidade do produto seriado". Como contexto teórico, está a consideração do autor de que a sociedade de consumo se encaminhava para uma era em que o consumidor seria instado a participar dos processos de produção, como coprodutor. Nesse ponto, a previsão de McLuhan se ajusta tanto à flexibilização dos sistemas e cadeias produtivos, acirrada no século XXI, quanto ao imaginário que reveste uma era em onde o consumo é central e 0 consumidor é retoricamente construído como o poder controlador que vai influenciar decisivamente nos processos que vão da produção ao consumo.
Como define Appadurai (1999), em sua releitura do conceito de fetiche da mercadoria de Marx, há tanto o fetiche da produção quanto o fetiche do consumo. 0 primeiro vai construir a aura que desvincula o produto de sua esfera produtiva e a lança ao plano mítico, onde 0 valor se afasta do uso e ganha novos patamares de valor de troca pelas camadas simbólicas que revestem a mercadoria. 0 fetiche do consumo, por sua vez, é o processo no qual o consumidor é alimentado pelo imaginário de que está no controle, quando na verdade tem uma gama de escolhas que se limita àquilo que a esfera produtiva lhe coloca à disposição. Entendemos que as redes digitais permitem que sujeitos elaborem sua produção de conteúdo com maior liberdade que outrora, e nessa instância em que se abrem espaços para sistemas colaborativos, também convivem estruturas anteriores a esses processos de flexibilização e interação mais amplos. Ainda se mantém a instauração do consumidor como parte da cadeia planejada de produção, mesmo em redes colaborativas de maior complexidade e alimentadas pela comunicação. Esse lugar do consumidor é o ponto de partida imaginário de tudo, a "razão de ser" das organizações. A retórica da satisfação dos desejos e dos quereres dos consumidores encobre as ambições pelo lucro e pela expansão do capital.

Em torno desse raciocínio, McLuhan discute o mundo do trabalho que, ao ser impactado decisivamente pela progressiva automação e pelos novos modos de vinculação dos sujeitos 
com a produção, é disseminado em atividades remuneradas e não remuneradas. Os papéis vivenciados se alternam entre 0 produtor identificado com uma corporação e com um sistema produtivo específicos; profissionais mediadores que tem por função estabelecer conexões comunicacionais com usuários, fornecedores, públicos dos mais diversos (dos serviços agregados às mercadorias a papéis como "caçadores de tendências" - cool hunters - e consultores de comportamento de grupos, comunidades, tribos, especialmente no que se refere às culturas juvenis); e até consumidores, que assumem a condição de coprodutores, prosumers, inseridos no processo produtivo como colaboradores. Essa variedade de possibilidades de compreensão das relações entre produtores e consumidores, inclusive na alternância, intersecções e sobreposições de papéis, é uma questão destacada por McLuhan em sua leitura da sociedade de consumo que se estabelece a partir da informatização progressiva e da compressão das categorias de tempo e espaço, decorrentes de convergências que hoje se consolidam em torno da mídia digital.

\section{Publicidade, consumo e trabalho segundo McLuhan}

Em sua leitura sobre a publicidade moderna, McLuhan dá relevo ao sentido de consumo simbólico que transcende a mercadoria. A maneira como os produtos se inserem em sistemas complexos de significação, que os aproximam dos afetos humanos e colocam em segundo plano suas funções, em parte é fruto dos cenários com que a publicidade emoldura o que é anunciado. Daí que a progressiva substituição dos produtos pela publicidade pensada por McLuhan (2005), antes de ser entendida em seu sentido literal, deve ser interpretada a partir da ideia de que o consumo da publicidade ganha certa autonomia na cena midiática contemporânea; os valores, estilos de vida, estímulos à ação da publicidade estabelecem um diálogo com 0 consumidor, independente do ato de compra. Os efeitos preconizados pela publicidade são amplificados, e a função da mercadoria passa a ser de desencadeadora de estados de espírito, de mobilizadora de afetos, de elos entre sujeitos. Um exemplo dessa discussão é a clássica campanha de MasterCard, "Priceless", em que o momento que não tem preço é o efeito de uma ressignificação de atos que passam por produtos mas que não dependem necessariamente deles. A dimensão humana do consumo, na leitura da publicidade, é sustentada por uma linguagem que é mercadoria em si mesma.

McLuhan (2005, p. 180) vai além desse raciocínio, ao afirmar que "esse tipo de novo ambiente de que dispomos, um ambiente de informação, eletricamente programado, converte todo o planeta numa máquina de ensinar, numa máquina de ensinar produzida pelo homem". 0 autor aponta para uma ideia de produção cooperada que vai gerar novos sentidos de comunidade: nesse ambiente construído pelo 
homem, o consumidor midiático realimenta o sistema com sua leitura, com sua presença, com seu aprendizado. 0 mundo construído pelo homem se apoia nessa comunhão de saberes e das práticas cotidianas, em torno das tecnologias e bens que transformam os sentidos humanos e são transformados continuamente, por vezes substituídos por novos aparatos tecnológicos. Nesse ambiente, o consumidor é instaurado a partir de uma lógica de duplo vínculo: simultaneamente, há um sentido privado e também tribal, coletivo na consciência de inclusão desenvolvida por este homem.

Baudrillard (2006) desenvolve raciocínio parecido através do conceito de presunção coletiva, que pressupõe cada ato de consumo: 0 bem consumido na esfera particular traz também significados de associação simbólica a um grupo, a uma tribo, ao compartilhamento de gostos e estilos de vida identificados com as mercadorias. Porém, Baudrillard parte de papéis bem delimitados em relação às esferas de produção $\mathrm{e}$ de consumo. McLuhan identifica que, na inserção do público como coprodutor, há a transformação de um consumidor passivo para a função de força de trabalho. A concepção de mundo do trabalho por McLuhan incorpora a tendência de que 0 emprego seria substituído pelo vínculo a papéis e projetos que, em última instância, seria uma junção indissociável da atividade laboral e do lazer: para defender essa tese, McLuhan (2005, p. 183) se vale da imagem do artista, que "nunca está trabalhando. Está fazendo o que gosta de fazer. Está se divertindo e desfrutando de seu lazer o tempo todo, especialmente quando trabalha mais intensamente".

Essa atmosfera do trabalho artístico, deslocada para o cenário contemporâneo, seria baseada numa cultura gerada em torno da mídia e da indústria do lazer, que é discutida por Morin (2006); 0 autor desenvolve seu pensamento por meio de um redimensionamento do diagnóstico da teoria crítica da Escola de Frankfurt, sobre os impactos da indústria cultural na sociedade. Nesse sentido, Morin defende que o imaginário social alimentado por essa cultura de massas vai estimular os sujeitos à busca de objetivos e sonhos que não são predeterminados por estruturas sociais e econômicas; a complexidade da combinação de ficção e realidade no cotidiano vai produzir sujeitos que não são moldados de forma homogênea, mas que são particularizados em sua forma de consumir e se apropriar dos estímulos da indústria cultural. Nesse quadro de relações entre trabalho e lazer, real e imaginário, identificamos esse consumidor que assume o papel de produtor e vai compreender sua atividade como lúdica, como algo relativo ao prazer, ao campo de seus interesses particulares. Voltaremos a essa discussão na análise do caso do projeto de produção cooperada do Fiat Mio, um modelo de "automóvel do futuro" que teve como principal plataforma a internet, no processo comunicacional a partir do qual se construiu 0 diálogo produtivo. 
Em síntese: o papel de coprodutor passa a ser uma estratégia comunicacional, uma forma de planejar o lugar do consumidor como parte da concepção de algo que lhe é destinado. A linguagem publicitária vai ressignificar esses polos da produção e do consumo em intersecção, em reversibilidade e sobreposição, como analisaremos a seguir por meio de comerciais e estratégias de publicização de mercadorias da indústria do automóvel.

\section{Sobre a metodologia aplicada ao corpus}

0 olhar analítico que aplicamos à publicidade de automóveis é baseado na Análise do Discurso (AD) de linha francesa. As visões de mundo, os valores, os recortes ideológicos que sustentam 0 mundo editado pela linguagem publicitária estão na perspectiva da metodologia da AD. 0 enfoque na materialidade da linguagem dá suporte à forma como compreendemos os textos culturais e sua relação com seu contexto social. 0 espírito do tempo atravessa os produtos que dele derivam; no caso da publicidade, podemos perceber as tensões entre discursos que caracterizam o cenário sociocultural que dá sentido a essa comunicação. Os deslizamentos dos sentidos, os pressupostos e subentendidos, as relações intertextuais e interdiscursivas, são elementos baseados no caráter dialógico da linguagem, como define Mikhail Bakhtin (1999). Para o autor, todo discurso estabelece sua dialogia com outros discursos que 0 antecederam, pois são estruturados a partir de já-ditos de uma cultura, utilizam-se de elementos pré-construídos para mobilizar a memória social e sustentar um repertório comum com seu público; o diálogo com os discursos contemporâneos é percebido na trama da linguagem, pois os sujeitos que assumem a produção linguística são também consumidores ativos dos discursos que permeiam o contexto social do qual fazem parte, assim como seus interlocutores; as conexões com discursos futuros são estabelecidas a partir da condição de que as mensagens procuram antecipar respostas, projetam ações futuras, ambicionam ser apropriadas pelos seus consumidores e, assim, transformar o outro, produzir afetações condizentes com seu projeto de fala.

Dessa forma, o estudo do ethos discursivo, que tem no pesquisador francês Dominique Maingueneau um de seus nomes mais destacados, dá suporte para a análise baseada no olhar para a interlocução projetada pela comunicação analisada, mesmo que isolada de seu processo, que implica na recepção e nos novos enunciados decorrentes dela - um processo contínuo, não circunscrito a um tempo e a um espaço determinados e disseminado pela trama social. A mensagem publicitária projeta a imagem do enunciador em traços de caráter e corporalidade; ou seja, faz emergir uma imagem do sujeito da enunciação, que adota um tom, um perfil psicológico, um corpo, que são percebidos através dos modos de dizer. Essa imagem produzida pelo discurso também se baseia nos afetos, nas paixões investidas na linguagem que implicam na forma como o outro é instaurado na comunicação; 
ou seja, o interlocutor é projetado pela mensagem que lhe é direcionada. 0 que vem ao encontro das ideias de André Gorz (2005), quando defende que os sistemas produtivos incluem o que 0 autor define como a produção de consumidores. A comunicação é parte do processo produtivo e vai para além dele, ao mediar a relação com os sujeitos, estimulados como consumidores de um projeto de fala que inclui a sua ação futura (seja a adesão ao universo simbólico de uma marca, a uma ideologia, à aquisição de uma mercadoria).

É a partir desse quadro que localizamos a comunicação publicitária como camada estética indissociável da mercadoria automóvel, pois é a partir da publicidade que o consumidor terá subsídios para localizar o produto em meio a um sistema dinâmico de valores presentes na sociedade, e a si mesmo em relação às ofertas do mercado. 0s elementos do design presentes na materialidade do automóvel podem sugerir características como "jovialidade", "aventura", "elegância", entre outras, mas é o posicionamento discursivo da publicização da mercadoria que vai ampliar o alcance da sugestão sensorial do design para compor sistemas mais complexos de ideias. A seguir, passamos a discutir esses elementos a partir da comunicação da indústria automobilística que tem como especificidade a referência explícita aos próprios processos produtivos, como estratégia metalinguística que vai traduzir a produção de automóveis à lógica do consumo. Roland Barthes (1987) define que "o mito é uma fala"; por meio da linguagem publicitária, refletimos sobre as mito-lógicas que atribuem significados aos automóveis em nosso tempo.

\section{Uma análise da publicidade da indústria automobilística no século XXI}

Como apontamos acima, a seleção das mensagens publicitárias para este estudo é baseada em uma característica comum: a presença das representações do processo produtivo do automóvel e o mundo do trabalho que o envolve. Sem a pretensão de uma abordagem quantitativa, elegemos peças que permitem perceber um amplo espectro de estratégias comunicacionais, que correspondem a categorias identificadas a partir do material recolhido previamente - composto por peças de publicidade de automóveis veiculadas na primeira década do século XXI. As três categorias que abarcam as peças selecionadas para este estudo são baseadas no caráter da interação proposta pela comunicação, através das formas de significação dos papéis de produtor e consumidor. Esta categorização tem como ponto de partida as questões colocadas por McLuhan, como discutimos anteriormente. Apresentamos abaixo cada uma das categorias e os filmes que são associados a elas, em suas especificidades e nos seus aspectos comuns.

\section{a) A produção em função do consumo particularizado}

Como característica dessa categoria, identificamos filmes que apresentam traduções 
Figura 1 Imagem do comercial “Cake” (UK, 2009)

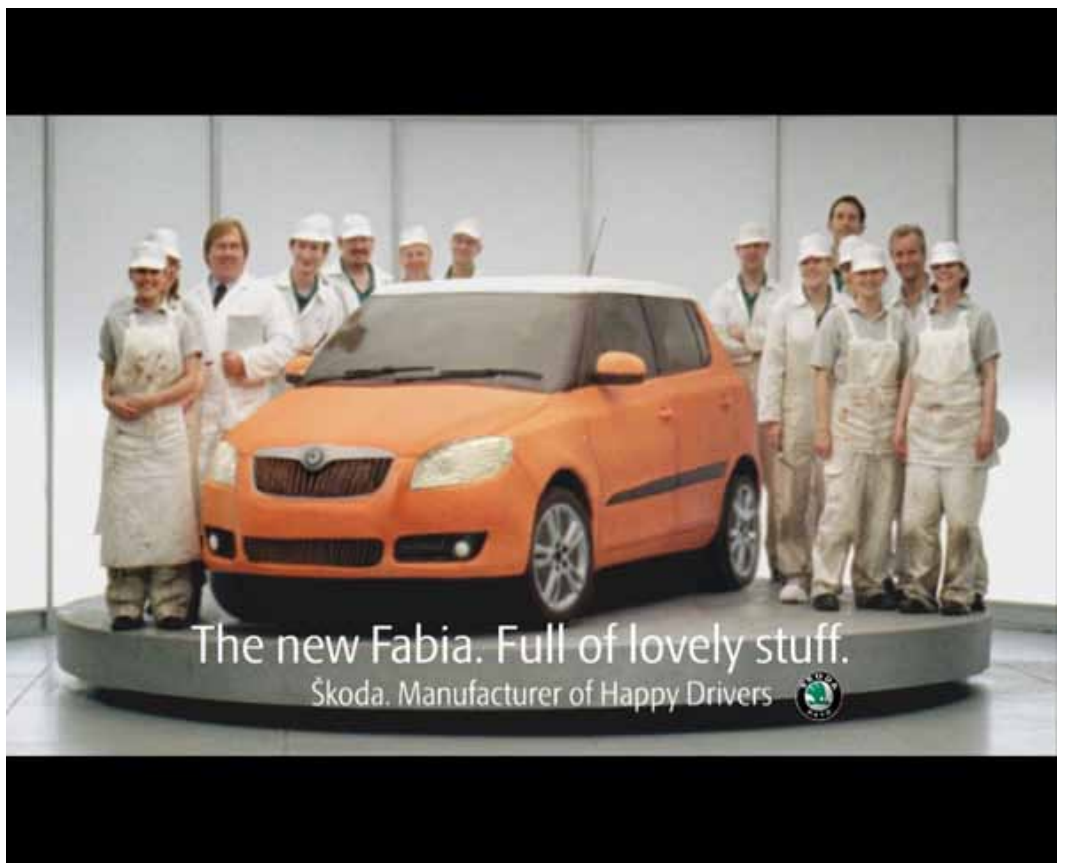

Fonte: SKODA AUTO, 2007.

da produção automobilística com papéis bem delimitados entre o que é a esfera da produção e o lugar do consumidor, para o qual a produção se volta no sentido de atenção a gostos, desejos, satisfações particularizadas, como discute Baudrillard (2006), ao analisar o anúncio da poltrona Airborne, em seu livro O sistema dos objetos. Para tanto, a produção se recria como espetáculo, como entretenimento. É o que vemos no filme Cake (United Kingdom, 2007) (Figura 1), para lançamento do new Fabia, modelo de automóvel da marca Skoda.

A fábrica automobilística é recriada na alegoria de uma confeitaria, em que funcionários produzem um bolo e recheios em grandes volumes. Tudo é feito com atenção artesanal; a presença humana se sobrepõe às máquinas e à automação. 0 ritmo é ditado por uma música antiga, uma marca intertextual: trata-se de $M y$ favourite things (Rodgers and Hammerstein), trilha sonora original do filme $A$ noviça rebelde (The Sound Of Music, dirigido por Robert Wise, 1965). A doce voz da atriz Julie Andrews, emoldurada ao som de orquestra, dá o tom leve e delicado do comercial, quando ela canta suas coisas favoritas, entre a natureza, animais e alimentos, fazendo a ode à felicidade derivada da experiência diária e do olhar positivo para os detalhes cotidianos, como antídoto à tristeza. Em meio a bases feitas de massa de bolo, coberturas doces como carcaça e faróis de geleia, chocolate como óleo, entre outras guloseimas que vão ser transformadas no 
automóvel, está o sentido do slogan que fecha o filme: "The new Fabia. Full of lovely stuff. / Skoda. Manufacturer of happy drivers".

0 comercial tem conexões com o imaginário de Afantástica fábrica de chocolate, obra literária que ganhou duas versões cinematográficas, a mais recente dirigida por Tim Burton (2005). A produção transcende a função do automóvel para chegar aos efeitos: dessa forma, assume o papel de produzir "motoristas felizes", na representação de um sistema que instaura 0 consumidor como centro de um processo todo voltado para sua felicidade, para a saciedade de seus desejos. 0 prazer e 0 sabor da infância associados aos doces são conotados em relação ao automóvel. 0 tom suave do filme traz o sentido de uma corporalidade delicada, feminina, que ressalta 0 imaginário do cuidado na produção associado ao artesanal e ao amor incondicional às crianças do personagem de Julie Andrews em The Sound of Music. 0 consumidor é derivado desses afetos, instaurado como sujeito a ser saciado em seus desejos, a se ajustar a esse sistema que se volta a ele como uma criança se aconchega nos braços da mãe. A corporação se faz humana, e o consumo do automóvel é sinônimo de prazer.

0 filme da Toyota chamado Made with a human touch (Denmark, 2008), identificase com esta categoria ao traduzir a produção para um espetáculo de sedução, na edição de imagens conduzida pela trilha sonora, a canção Heart of glass (1978), da banda Blondie. 0 tom sedutor do vocal feminino de Debbie Harry, aliado à batida dançante da música, ditam 0 ritmo do trabalho, em processos simultâneos de produção de modelos distintos da marca, que se alternam nas imagens. 0 ambiente tem estética futurista, em combinações variadas das cores da marca - branco, vermelho e preto. Momentos produtivos que constroem o caráter envolvente da marca Toyota: belas mulheres de roupas justas, dançando sensualmente enquanto pintam a carcaça de um automóvel; operários em sincronia de movimentos diante de uma esteira de montagem; uma pista de provas em que as manobras circulares do automóvel são apresentadas em câmera lenta; 0 salto acrobático de um homem, lançando-se de uma plataforma para testar os air bags dispostos no chão. Como ponto culminante do filme, há o momento em que centenas de borboletas vermelhas, a partir do acionamento de um botão, cobrem completamente a carcaça do modelo Prius disposto no espaço.

No filme da Toyota, 0 "toque humano" combina 0 sentido de artesania à produção seriada feita por seres humanos quase automatizados; o ethos que deriva desta comunicação tem um tom sedutor, que alia traços tecnológicos à marca humana. A alegoria da produção busca traduzir os efeitos do consumo; para isso, reveste-se com a estética do espetáculo, da moda, da plástica do esporte acrobático, da natureza domesticada - elementos em convergência que são unificados em torno do conceito, que ressalta a presença humana. A 
Figura 2 Imagem do comercial de lançamento do Fiat 500 no Brasil (2009)

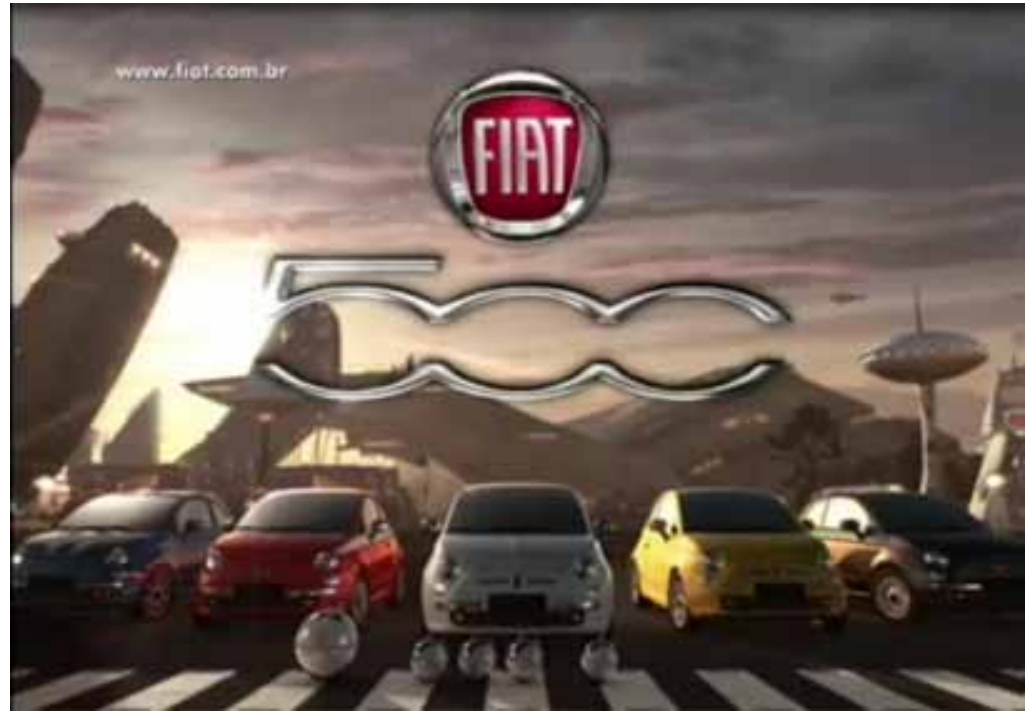

Fonte: FIAT 500..., 2009.

produção novamente aponta para os sentidos do consumidor e 0 instaura como beneficiário deste sistema no plano individual.

\section{b) A produção em função do consumo coletivo e de causas sociais}

Esta categoria tem como elemento característico a significação dos papéis da produção e do consumo como parte de um processo social mais amplo; se é possível localizarmos atribuições específicas do produtor e do consumidor em um primeiro momento, ambos são identificados no processo colaborativo de construção de um cenário ideal, de uma questão coletiva, de uma causa social, de uma utopia de consumo. A publicidade constrói teses sobre o mundo de hoje e sobre o futuro, pressupondo funções compartilhadas, nos papéis que devem ser assumidos com vistas ao bem-estar da coletividade.

Como representante da categoria, selecionamos o filme produzido para o lançamento do Fiat 500 no mercado brasileiro, no ano de 2009 (Figura 2). Modelo antigo da marca Fiat (sua primeira versão é da década de 1950, um carro popular que teve importância no cenário de reconstrução italiana pós-Segunda Guerra Mundial), tem sua releitura para o modelo atual no ano de 2007, modernizado em suas linhas e acrescido de componentes tecnológicos avançados. 0 comercial em questão é todo produzido em animação, com o cenário futurista que tem na automatização sua principal característica. A trilha sonora é uma versão da canção "Ob-La-Di, Ob-La-Da", lançada originalmente pelos Beatles no clássico White Album (1968). 0 tom é alegre, divertido, 
calorosamente humano, tornando complexa a leitura do mundo dominado pela tecnologia. A imagem do carro surge em meio a duas mãos gigantes no céu, como uma esfera de luz, podendo ser associada a uma obra divina. Deslocandose inicialmente em meio a um deserto, o Fiat 500 chega ao espaço urbano idealizado em torno da tecnologia futurista. Nos canteiros da autoestrada, margaridas mecânicas equipadas com câmeras vigiam a passagem do automóvel. 0 discurso verbal da locução demarca 0 sentido do futuro como um cenário sonhado no tempo presente: "Esse é um novo tempo. Um tempo em que todos podemos nos sentir mais livres, respirar melhor".

0 automóvel é abastecido por uma bomba de combustível acoplada a um braço mecânico - somente uma gota é colocada no tanque, conotando de forma hiperbólica a economia do consumo do Fiat 500. A locução sincronizada a esta imagem a semantiza como um pequeno gesto com significado grandioso: "Um tempo em que não dividimos apenas sonhos, mas também o planeta em que vivemos, o espaço em que circulamos, as viagens que fazemos". Uma nave espacial decola; 0 automóvel faz manobras para ultrapassar robôs gigantes que caminham pela estrada, até atravessar um túnel repleto de formas geométricas coloridas: "O tempo em que você é que manda na tecnologia, e não ela em você". Em uma espécie de lava-rápido do futuro, o Fiat 500 é preparado por máquinas e por monstros cobertos completamente por pelos que, assim como os braços mecânicos, estão a serviço da produção, na cena acompanhada do texto: "Esse tempo nos une e nos torna mais parecidos, ao mesmo tempo em que nos diferencia e faz cada um de nós único, especial". Ao retornar à estrada, vemos somente automóveis do modelo anunciado, que param no farol, à frente de uma faixa de pedestres, para a passagem de robôs que se assemelham, em seus movimentos e na sua proporção, a um adulto seguido por um grupo de crianças, quando entra a assinatura da campanha: "Fiat 500. O carro do nosso tempo".

E que tempo é esse preconizado pelo comercial? Um tempo em que a produção de automóveis é conotada como a fabricação de um mundo novo. Um futuro transportado para o presente, em que a tecnologia serve para libertar, mas que simultaneamente promove a padronização de bens e ações, a automatização da produção, 0 desaparecimento do trabalhador. Tempo em que a utopia de um mundo melhor é traduzida em pequenos gestos de consumo, como a economia de combustível. Tempo sonhado em torno da harmonia entre produção e consumo, em papéis ora delimitados, ora sobrepostos no plano da construção de um cenário idealizado. A comunidade imaginada pela publicidade é sustentada pelo ethos utópico, de corporalidade tecnológica e espírito humanista - este último associado ao imaginário do compartilhamento de ideais entre produtores e consumidores. Nada mais paradoxal, se considerarmos que, em última instância, 0 automóvel de passeio é uma saída particularizada 
para o problema coletivo do transporte nas grandes metrópoles mundiais. De forma contraposta à tendência apontada por McLuhan a respeito do destino do automóvel, que seria substituído por outras tecnologias, ele se recria pela publicidade e se lança ao futuro, em um mundo que dissolve utopias para serem consumidas de forma cômoda, confortável, aqui e agora.

\section{c) A produção em cooperação com o consumidor}

A terceira categoria tem correlação mais estreita com as tendências do marketing apontadas por McLuhan: a incorporação do consumidor no processo de produção automobilística é o mote do projeto Fiat Mio (Figura 3). A ação tem como princípio o desenvolvimento do Fiat Concept Car III (FCC-III), para o qual foi criado o site http://www.fiatmio.cc/ - plataforma virtual por meio da qual são manifestadas as opiniões dos consumidores sobre como deveria ser 0 automóvel do futuro. 0 processo se estendeu por todo 0 ano de 2010, tendo como resultado a produção do protótipo apresentado no Salão do Automóvel da cidade de São Paulo, no mês de outubro do mesmo ano. 0 slogan do comercial veiculado na TV remetia ao site, e dava 0 tom da iniciativa: "A Fiat convida você a criar um carro. Um carro para chamar de seu". Destacamos os aspectos comunicacionais mais relevantes do projeto Fiat Mio, uma vez que este se caracteriza por uma estratégia de publicização que expande o formato publicitário tradicional. A imersão do consumidor no papel de coprodutor é realizada na condição de desenvolvedor de ideias: os números apresentados pela Fiat são grandiosos nesse sentido. 0 projeto que se iniciou na filial brasileira da montadora italiana conta com 17.000 pessoas cadastradas no site, originárias de 160 países, contabilizando 10.666 ideias enviadas até 0 dia 11 de abril de 2011 (dados

Figura 3 Imagem do Projeto Fiat Mio (2010)

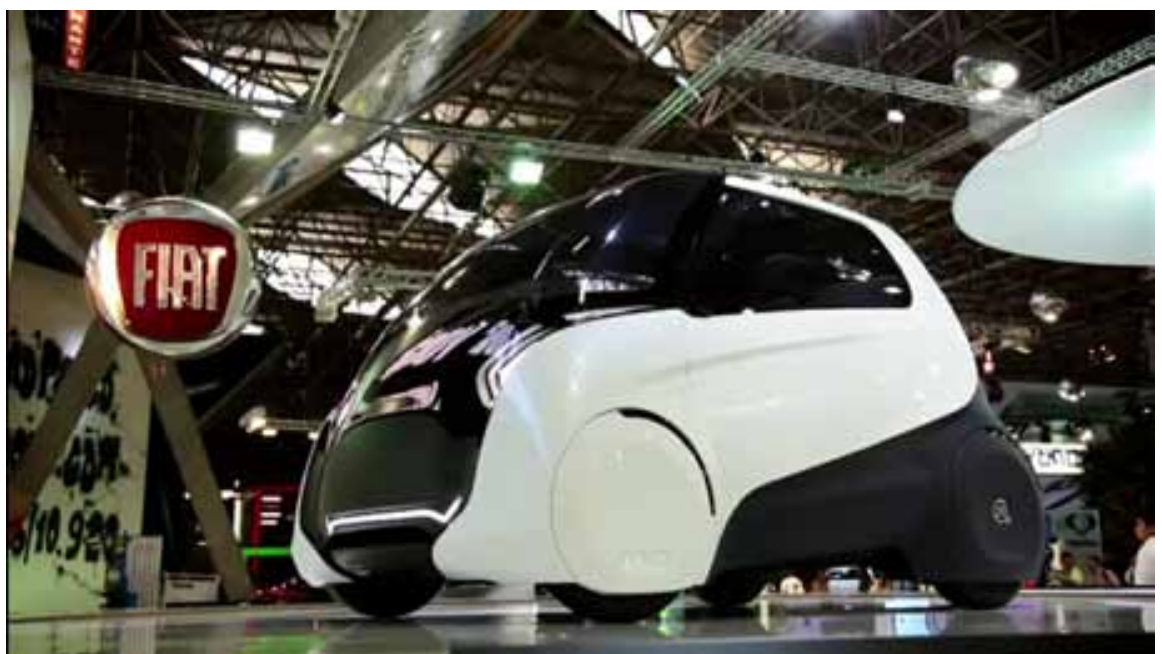

Fonte: FIAT, 2009. 
do site). 0 consumidor é classificado em seu desempenho, medido pela quantidade de ideias compartilhadas e comentários feitos a partir de suas intervenções, no sistema de pontuação definido pelos coordenadores do projeto.

Um dos aspectos mais interessantes dessa estratégia comunicacional é que o sistema produtivo, definido como compartilhado, é revelado em seus significados por meio das vozes dos trabalhadores da Fiat, nos making ofs que acompanham o processo e o tornam público por meio do site e no YouTube. De fevereiro de 2010 a janeiro de 2011, foram realizados 16 filmes dos bastidores da produção, que têm como protagonistas os projetistas, engenheiros e demais trabalhadores da Fiat envolvidos no projeto Mio. Suas falas sinalizam que as ideias dos usuários do site serviram de ponto de partida, mas que também coube a eles a interpretação daquilo que "gostaram mais", ou que consideraram viáveis, ou ainda que interpretaram como sendo "aquilo que está por trás" das opiniões dos consumidores. Somente em dois filmes os coprodutores aparecem: quando o protótipo é apresentado no Salão de Automóvel de São Paulo; e no filme que registra a visita de alguns dos colaboradores para uma visita à fábrica e um jantar, oferecido pela montadora como reconhecimento pelos serviços prestados. Temos, então, o reality show da produção que constrói a imagem mitificada dos produtores da Fiat, consagrados simbolicamente em sua missão heróica: traduzir os anseios, opiniões e "necessidades" dos consumidores em apuro técnico aplicado a um projeto de futuro. A felicidade derivada da atividade laboral é expressa pelas feições sorridentes, pelas falas carregadas de entusiasmo, de emoção, de motivação.

Incorporar o consumidor como coprodutor revelase como tendência: 0 trabalho não remunerado é vampirizado pelo processo produtivo, que por sua vez ganha ares de legitimidade por se respaldar nas opiniões e na aprovação do consumidor, que, nas etapas mais avançadas, é convocado a fazer escolhas entre opções delimitadas pela produção. 0 ethos flexível da Fiat, edificado sobre vozes de produtores e consumidores de forma dialógica, revela, nos making ofs, o reality show de seu próprio trabalho, seu caráter humilde e ao mesmo tempo heróico, capaz de ouvir, reagir e produzir fascinação para sujeitos que sonham o futuro, agenciados pelas estratégias corporativas.

\section{Considerações finais}

Marshall McLuhan, em suas discussões sobre a publicidade e sobre 0 automóvel, aponta para 0 sentido das extensões humanas que envolvem o consumo e sua retórica. Aproximamos a esses temas um terceiro vetor também presente nas questões colocadas pelo autor: o mundo do trabalho e as tendências do setor produtivo. Através da análise do discurso publicitário, compreendemos elementos que compõem 
o imaginário alimentado pela indústria automobilística no século XXI. Procuramos identificar as mito-lógicas que atribuem significados às esferas da produção e do consumo, por meio da categorização definida a partir da leitura prévia do corpus selecionado para o estudo, e pela exemplificação de cada categoria na análise de quatro estratégias distintas. Chegamos a níveis de interação entre produtores e consumidores, projetados pela comunicação com papéis delimitados e também em zonas de intersecção.

A produção se molda à lógica do consumo ao ser representada como espetáculo; abordagens particularizadas de atenção a desejos e "necessidades", e construções em torno de ideais coletivos e utópicos, são formas distintas de vincular o consumidor como parte do sistema produtivo. Projetos de futuro e experiências imediatas se combinam para conquistar públicos, de acordo com 0 universo simbólico das marcas. A estratégia de incorporação do consumidor como produtor atinge seu grau máximo no projeto do Fiat Mio, que, se apresenta inovações interessantes que apontam para um futuro da cultura corporativa, também deixa revelar as formas de alienação da força de trabalho por meio de propostas de sedução, de aspectos lúdicos, de pequenas recompensas e de novos sentidos atribuídos a práticas antigas do mercado, como a pesquisa com consumidores elevada ao status de produção colaborativa.

\section{Referências}

ANDERSON, Benedict. Comunidades imaginadas: reflexões sobre a origem e a expansão do nacionalismo. Lisboa: Edições 70, 2005.

APPADURAI, Arjun. Disjunção e diferença na economia cultural global. In: FEATHERSTONE, Mike (Org.). Cultura global: nacionalismo, globalização e modernidade. Petrópolis, RJ: Vozes, 1999. p. 311-327.

BAKHTIN, Mikhail. Marxismo e filosofia da

linguagem. São Paulo: Hucitec, 1999.

BARTHES, Roland. Mitologias. São Paulo: Difel, 1987.

BAUDRILLARD, Jean. 0 sistema dos objetos. São

Paulo: Perspectiva, 2006.

BENJAMIN, Walter. Paris, capital do século XIX. In: KOTHE, Flávio (Org.). Walter Benjamin: sociologia. São Paulo: Ática, 1991. p. 31-43.

BERGER, John. Modos de ver. Barcelona: Gustavo Gilli, 1974.

DAHL, Roald. A fantástica fábrica de chocolate. São Paulo: Martins Fontes, 2010.

CHARLIE and the Chocolate Factory. Diretor: Tim Burton. Roteiro: John August. Intérpretes: Johnny Depp e Helena Bonham Carter. [S.l.]: Warner Bros., 2005. (115 min.), son. color. Lançado em DVD no Brasil com o título "A fantástica fábrica de chocolate". Baseado em livro de Roald Dahl.

FIAT. Projeto Fiat Mio. 2009. Disponível em: < http:// www.fiatmio.cc/>. Acesso em: 9 fev. 2012.

FIAT 500: comercial de lançamento no Brasil. 2009. Disponível em: <http://www.youtube.com/ watch?v=HfezAZhiLDQ>. Acesso em: 9 fev. 2012.

GORZ, André. 0 imaterial: conhecimento, valor e capital. São Paulo: Annablume, 2005.

HARRY, Deborah; STEIN, Chris. Heart of Glass. Intérprete: Blondie. In: Parallel Lines. Produtor: Mike 
Chapman. [S.l.]: Chrysalis, 1979. 1 disco sonoro, 33 1/3 rpm, Lado B, faixa 9 .

LENNON, John; MCCARTNEY, Paul. Ob-La-Di, Ob-LaDa. Interpretada por The Beatles. In: The Beatles. Produtor: George Martin. [S.l.]: Apple Records, Parlophone, EMI, 1968. 1 disco sonoro, 33 1/3 rpm, Lado A, faixa 4. Também conhecido como "White Album Disco 1".

MAINGUENEAU, Dominique. Análise de textos de comunicação. São Paulo: Cortez, 2001.

MARX, Karl. Trabalho estranhado e propriedade privada. In: ANTUNES, Ricardo. A dialética do trabalho: escritos de Marx e Engels. São Paulo: Expressão Popular, 2004. p. 173-195.

McLUHAN, Marshall. Os meios de comunicação como extensões do homem (understanding media). São Paulo: Cultrix, 1995.

McLuhan por McLuhan: conferências e entrevistas (understanding me). Rio de Janeiro: Ediouro, 2005.

MORIN, Edgar. Cultura de massas no século XX, volume 1: neurose. Rio de Janeiro: Forense, 2006. ORLANDI, Eni. Análise de discurso: princípios \& procedimentos. Campinas, SP: Pontes, 2001.

SKODA AUTO, 2007. Skoda Cake Advert Scoops

Industry Prize. 2007. disponível em: <http:// www.vwvortex.com/artman/publish/skoda_news/ article_2112.shtml>.Acesso em: 27 set. 2011. THE SOUND of Music. Diretor e Produtor: Robert Wise. Roteiro: Ernest Lehman. Musical book: Howard Lindsay e Russel Crouse. Trilha sonora: Richard Rodgers e 0scar Hammerstein II. Intérpretes: Julie Andrews e Christopher Plummer. [S.l.]: 20th Century Fox, 1965. (174 min.), son. color. Lançado em DVD no Brasil com o título "A noviça rebelde". 


\section{For-consumption images of the automotive industry: the world of work through the lens of advertising communication}

\section{Abstract}

This paper analyzes advertising communication strategies of the automotive industry in the early 21st century, mainly from the standpoint of the representations of its productive processes and meanings of consumption. The theoretical framework discusses McLuhan's theory on cultural aspects of automobiles, production trends and new roles to be assumed by consumers, in the transformations promoted by modern marketing. The theoreticalmethodological approach of the French line of Discourse Analysis was adopted in the reflection on the corpus.

\section{Keywords}

Communication and Consumption.

Communication and Work. Advertising. Automobile brands. Marshall McLuhan.

\section{Imágenes de la industria automotriz para el consumo: el mundo laboral a través del lente de la comunicación publicitaria}

\section{Resumen}

Este artículo analiza las estrategias de la comunicación publicitaria de la industria de automóviles a principios de siglo XXI, tenendo como ejes principales las representaciones de sus procesos de producción y los significados del consumo. La discusión teórica trata de las tesis de McLuhan sobre los aspectos culturales de los automóviles, las tendencias de la producción y los nuevos roles que debe asumir el consumidor, en los cambios promovidos por el marketing moderno. El enfoque teórico y metodológico del análisis del discurso de la línea francesa se adoptó en el pensamiento sobre el corpus.

\section{Palabras Clave}

Comunicación y consumo. Comunicación y trabajo. Publicidad. Marcas de automóviles. Marshall McLuhan. 


\section{Expediente}

A revista E-Compós é a publicação cientíica em formato eletrônico da Associação Nacional dos Programas de Pós-Graduação em Comunicação (Compós). Lançada em 2004, tem como principal finalidade difundir a produção acadêmica de pesquisadores da área de Comunicação, inseridos em instituições do Brasil e do exterior.
E-COMPÓS I www.e-compos.org.br I E-ISSN 1808-2599

Revista da Associação Nacional dos Programas

de Pós-Graduação em Comunicação.

Brasília, v.14, n.3, set./dez. 2011.

A identificação das edições, a partir de 2008

passa a ser volume anual com três números.
CONSELHO EDITORIAL

Afonso Albuquerque, Universidade Federal Fluminense, Brasil Alberto Carlos Augusto Klein, Universidade Estadual de Londrina, Brasil Alex Fernando Teixeira Primo, Universidade Federal do Rio Grande do Sul, Brasil Ana Carolina Damboriarena Escosteguy, Pontifícia Universidade Católica do Rio Grande do Sul, Brasil

Ana Gruszynski, Universidade Federal do Rio Grande do Sul, Brasil Ana Silvia Lopes Davi Médola, Universidade Estadual Paulista, Brasil André Luiz Martins Lemos, Universidade Federal da Bahia, Brasil Ângela Freire Prysthon, Universidade Federal de Pernambuco, Brasil Angela Cristina Salgueiro Marques, Faculdade Cásper Líbero (São Paulo), Brasil Antônio Fausto Neto, Universidade do Vale do Rio dos Sinos, Brasil Antonio Carlos Hohlfeldt, Pontifícia Universidade Católica do Rio Grande do Sul, Brasil Antonio Roberto Chiachiri Filho, Faculdade Cásper Líbero, Brasil Arlindo Ribeiro Machado, Universidade de São Paulo, Brasil Arthur Autran Franco de Sá Neto, Universidade Federal de São Carlos, Brasil Benjamim Picado, Universidade Federal Fluminense, Brasil César Geraldo Guimarães, Universidade Federal de Minas Gerais, Brasil Cristiane Freitas Gutfreind, Pontifícia Universidade Católica do Rio Grande do Sul, Brasil Denilson Lopes, Universidade Federal do Rio de Janeiro, Brasil Denize Correa Araujo, Universidade Tuiuti do Paraná, Brasil Edilson Cazeloto, Universidade Paulista , Brasil Eduardo Peñuela Cañizal, Universidade Paulista, Brasil Eduardo Vicente, Universidade de São Paulo, Brasil Eneus Trindade, Universidade de São Paulo, Brasil Erick Felinto de Oliveira, Universidade do Estado do Rio de Janeiro, Brasil Florence Dravet, Universidade Católica de Brasília, Brasil Francisco Eduardo Menezes Martins, Universidade Tuiuti do Paraná, Brasi Gelson Santana, Universidade Anhembi/Morumbi, Brasil Gilson Vieira Monteiro, Universidade Federal do Amazonas, Brasil Gislene da Silva, Universidade Federal de Santa Catarina, Brasil Guillermo Orozco Gómez, Universidad de Guadalajara Gustavo Daudt Fischer, Universidade do Vale do Rio dos Sinos, Brasil Hector Ospina, Universidad de Manizales, Colômbia Herom Vargas, Universidade Municipal de São Caetano do Sul, Brasil leda Tucherman, Universidade Federal do Rio de Janeiro, Brasi Inês Vitorino, Universidade Federal do Ceará, Brasil Janice Caiafa, Universidade Federal do Rio de Janeiro, Brasi Jay David Bolter, Georgia Institute of Technology Jeder Silveira Janotti Junior, Universidade Federal de Pernambuco, Brasil João Freire Filho, Universidade Federal do Rio de Janeiro, Brasi John DH Downing, University of Texas at Austin, Estados Unido José Afonso da Silva Junior, Universidade Federal de Pernambuco, Brasil

\section{COMISSÃO EDITORIAL}

Adriana Braga I Pontifícia Universidade Católica do Rio de Janeiro, Brasil Felipe Costa Trotta I Universidade Federal de Pernambuco, Brasil

CONSULTORES AD HOC

Édison Gastaldo, Universidade Federal Rural do Rio de Janeiro, Brasil

EDIÇÃO DE TEXTO E RESUMOS I Susane Barros

SECRETÁRIA EXECUTIVA I Juliana Depiné

EDITORAÇÃo ELETRÔNICA I Roka Estúdio

TRADUÇÃo I Sieni Campos e Robert Finnegan
José Carlos Rodrigues, Pontifícia Universidade Católica do Rio de Janeiro, Brasil José Luiz Aidar Prado, Pontifícia Universidade Católica de São Paulo, Brasil José Luiz Warren Jardim Gomes Braga, Universidade do Vale do Rio dos Sinos, Brasi Juremir Machado da Silva, Pontifícia Universidade Católica do Rio Grande do Sul, Brasil Laan Mendes Barros, Universidade Metodista de São Paulo, Brasil Lance Strate, Fordham University, USA, Estados Unidos Lorraine Leu, University of Bristol, Grã-Bretanha Lucia Leão, Pontifícia Universidade Católica de São Paulo, Brasil Luciana Panke, Universidade Federal do Paraná, Brasil Luiz Claudio Martino, Universidade de Brasilia, Brasil Malena Segura Contrera, Universidade Paulista, Brasil Márcio de Vasconcellos Serelle, Pontifícia Universidade Católica de Minas Gerais, Brasil Maria Aparecida Baccega, Universidade de São Paulo e Escola Superior de Propaganda e Marketing, Brasil

Maria das Graças Pinto Coelho, Universidade Federal do Rio Grande do Norte, Brasil Maria Immacolata Vassallo de Lopes, Universidade de São Paulo, Brasil Maria Luiza Martins de Mendonça, Universidade Federal de Goiás, Brasi Mauro de Souza Ventura, Universidade Estadual Paulista, Brasil Mauro Pereira Porto, Tulane University, Estados Unidos Nilda Aparecida Jacks, Universidade Federal do Rio Grande do Sul, Brasil Paulo Roberto Gibaldi Vaz, Universidade Federal do Rio de Janeiro, Brasi Potiguara Mendes Silveira Jr, Universidade Federal de Juiz de Fora, Brasil Renato Cordeiro Gomes, Pontifícia Universidade Católica do Rio de Janeiro, Brasil Robert K Logan, University of Toronto, Canadá

Ronaldo George Helal, Universidade do Estado do Rio de Janeiro, Brasil Rosana de Lima Soares, Universidade de São Paulo, Brasil Rose Melo Rocha, Escola Superior de Propaganda e Marketing, Brasil Rossana Reguillo, Instituto de Estudos Superiores do Ocidente, Mexico Rousiley Celi Moreira Maia, Universidade Federal de Minas Gerais, Brasil Sebastião Carlos de Morais Squirra, Universidade Metodista de São Paulo, Brasil Sebastião Guilherme Albano da Costa, Universidade Federal do Rio Grande do Norte, Brasil

Simone Maria Andrade Pereira de Sá, Universidade Federal Fluminense, Brasi Tiago Quiroga Fausto Neto, Universidade de Brasília, Brasil Suzete Venturelli, Universidade de Brasília, Brasil Valério Cruz Brittos, Universidade do Vale do Rio dos Sinos, Brasil Valerio Fuenzalida Fernández, Puc-Chile, Chile Veneza Mayora Ronsini, Universidade Federal de Santa Maria, Brasil Vera Regina Veiga França, Universidade Federal de Minas Gerais, Brasil Valerio Fuenzalida Fernández, Puc-Chile, Chile Veneza Mayora Ronsini, Universidade Federal de Santa Maria, Brasil Vera Regina Veiga França, Universidade Federal de Minas Gerais, Brasil

COMPÓS I www.compos.org.br Associação Nacional dos Programas de Pós-Graduação em Comunicação

Presidente Julio Pinto

Pontifícia Universidade Católica de Minas Gerais, Brasil juliopinto@pucminas.br

Vice-presidente

Itania Maria Mota Gomes

Universidade Federal da Bahia, Brasil

itania@ufba.br

Secretária-Geral

Inês Vitorino

Universidade Federal do Ceará, Brasil

inesvict@gmail.com 